\title{
Interaction of Subordinate Staff Management and Factors of Economic Performance of Companies in the Bulgarian Mining and Quarrying Sector
}

\author{
Milena Tepavicharova ${ }^{1}$, Ludmila Aleksejeva ${ }^{2}$, and Radostin Vazov $^{3}$ \\ ${ }^{1}$ Higher School of Security and Economics - Plovdiv, 13 Kuklensko Shose Blvd., 4004 Plovdiv \\ ${ }^{2}$ Daugavpils University, Parades st. 1, Daugavpils, LV-5401, Latvia \\ ${ }^{3}$ VUZF University, 1 Gusla Street, 1618 Ovcha Kupel Square, Sofia, Bulgaria
}

\begin{abstract}
The achievement of high production and economic results in the economic entities of the mining industry in Bulgaria is possible only through the elaboration of an effective system for management of the subordinate personnel. In the context of the systematic approach, it is of paramount importance to outline the factors for subordinate staff management which have a positive impact on the economic status of the business organizations. Building a model of factors for subordinate staff management enables us to identify and implement multiple approaches and mechanisms. This creates opportunities for improving the management of the subordinate personnel, which has a positive impact on the development of the mining companies. The purpose of this article is to study the factors for subordinate staff management and to elaborate a model of those which have a direct and indirect impact on the production and economic results of the companies in the quarrying industry in Bulgaria. The article is structured in two main sections. The first includes an analysis of the factors of management of the subordinate workforce, examining the connections and relations with the economic performance of the companies. The second section introduces a model of management factors which prove to be particularly relevant to achieving high economic performance in the Bulgarian mining companies.
\end{abstract}

\section{Introduction}

The extractive industry in Bulgaria is a small part of the economy; never the less it achieves substantial economic efficiency. Apart from the purely financial direct benefits for the state, such as concession fees and taxes on corporate profits, this efficiency leads to relatively high wages and substantial social benefits for the employees. The development of the economic organizations in the sector is largely determined by the available production resources, their quality and the efficiency of their use [1-3]. One of the main resources, clearly standing apart from the rest, is the human resource. It possesses a certain level of qualification and professional development, which are crucial for increasing productivity and well-being. In this respect, the achievement of high production and economic results in the economic entities of the mining industry in Bulgaria is possible only through the elaboration of an 
effective system for management of the subordinate personnel. In the context of the systematic approach, it is of paramount importance to outline the factors for subordinate staff management which have a positive impact on the economic status of the business organizations.[4]

Building a model of factors for subordinate staff management enables us to identify and implement multiple approaches and mechanisms [5-8]. This creates opportunities for improving the management of the subordinate personnel, which has a positive impact on the development of the mining companies.

The justification of the factors, as well as their interaction and impact on the achievement of positive production and economic performance, is of crucial value for the establishment of a system for the selection, training and professional development of the subordinate workers in the mining organizations. In this regard, the study of profitable companies could help determine the degree of correlation between the various factors for the management of subordinate staff and the final economic results.

The purpose of this article is to study the factors for subordinate staff management and to elaborate a model of those which have a direct and indirect impact on the production and economic results of the companies in the quarrying industry in Bulgaria.

The article is structured in two main sections. The first includes an analysis of the factors of management of the subordinate workforce, examining the connections and relations with the economic performance of the companies. The second section introduces a model of management factors which prove to be particularly relevant to achieving high economic performance in the Bulgarian mining companies.

\section{Material and method}

The efficiency of its management, directly reflected on the final economic results, plays an important role for the adequate functioning of any business organization. Such results carry information on the combined outcome of skillful management work and the effective use of the subordinate staff. In this regard, the generation of profit is considered and appears a key value indicator expressing the degree of management efficiency in the organizations.

The study and analysis of the management in the profit-making businesses can reveal to us the real opportunities for optimal use and development of the employees, in order to achieve higher productivity and competitiveness. In this sense, profit is regarded as a function of adequately-made management decisions regarding the management of the subordinate staff in the production process and in the production marketing. That is why, in the present study, profit is considered to be a major indicator of management effectiveness.

During the research and analysis of the condition and problems of the subordinate workforce in the mining industry in Bulgaria, we studied 31 different in size, status and form of ownership business organizations. According to their size, the surveyed companies are divided into three groups, namely: From 1 to 50 employees - 20.05\%; From 51 to 100 employees - 46.77\%; More than 101 employees - 33.18\%.

The selection of the companies is based on the high economic performance achieved by them, i.e. the declared profit for the research period. The characteristic features and conditions under which the production activities are carried out in these business organizations present an objective view of the condition, development and use of the subordinate staff of the quarrying industry in Bulgaria. Taking into account their characteristics is a key point in developing a model for effective management of the subordinate employees.

The effect and interaction of the fundamental management factors influencing the amount of profit in the businesses is studied using correlation analysis under the Pearson method. It calculates and analyzes the correlation coefficients of the following factors: 
- Number, structure and professional experience of the employees - revealing the age and gender structure, as well as the vocational experience of the subordinate staff;

- Educational and professional-qualification profile - considering the level of education and qualification of the employees in the business organizations;

- Employee efficiency - revealing labor productivity and its impact on the positive economic results;

- Remuneration and work incentives - representing the level of basic and additional remuneration, in accordance with the Labor Code and the internal regulations of the business organizations in focus.

The factors in scope are in line with the specific features of the subordinate staff. (Table 1). It includes all employees in the company who do not have the authority to make management decisions, but must coordinate their actions with the manager responsible for the specific activity.

Table 1. Management factors for the subordinate staff.

\begin{tabular}{|c|c|c|c|}
\hline \multicolumn{4}{|c|}{ Management factors for the subordinate staff } \\
\hline $\begin{array}{c}\text { Number, structure and } \\
\text { professional experience } \\
\text { of the employees }\end{array}$ & $\begin{array}{c}\text { Educational and } \\
\text { professional- } \\
\text { qualification profile }\end{array}$ & $\begin{array}{l}\text { Employee } \\
\text { efficiency }\end{array}$ & $\begin{array}{l}\text { Remuneration and work } \\
\text { incentives }\end{array}$ \\
\hline $\begin{array}{l}\text { 1.Number of employees in } \\
\text { the organization; } \\
\text { a/ Permanent subordinate } \\
\text { staff; } \\
\text { персонал; } \\
\text { b/ Temporary staff. } \\
\text { 2. Age structure } \\
\text { a/ from } 15 \text { to } 35 \text { years old; } \\
\text { b/ } 36 \text { to } 55 \text {; } \\
\text { c/ Over } 56 \\
\text { 3. Gender } \\
\text { a/ Men; b/ Women. } \\
\text { 4. Work experience } \\
\text { a/ up to } 15 \text { yrs.; } \\
\text { b/ from } 16 \text { to } 35 \text { yrs.; } \\
\text { c/ } 36 \text { and over }\end{array}$ & $\begin{array}{l}\text { 1.Educationa } \\
\text { a/ elementary } \\
\text { educational level; } \\
\text { b/ basic educational } \\
\text { level; } \\
\text { c/ secondary general } \\
\text { level; } \\
\text { d/ vocational } \\
\text { secondary education; } \\
\text { e/ higher education } 2 \text {. } \\
\text { Work experience on } \\
\text { the specialty } \\
\text { a/ up to } 15 \text { yrs.; } \\
\text { b/ from } 16 \text { to } 35 \text { yrs.; } \\
\text { c/ } 36 \text { and over }\end{array}$ & $\begin{array}{l}\text { 1. Produced } \\
\text { output/ BGN. } \\
\text { 2.Produced } \\
\text { output per } \\
\text { one } \\
\text { employee/ } \\
\text { BGN. } \\
\text { 3. Produced } \\
\text { output per } \\
\text { one person- } \\
\text { day/ BGN. } \\
\text { 4. Produced } \\
\text { output per } \\
\text { person-day of } \\
\text { the } \\
\text { subordinate } \\
\text { staff/ BGN. } \\
\end{array}$ & $\begin{array}{l}\text { 1. Basic salary and social } \\
\text { security of employees in } \\
\text { the BGN / Month. } \\
\text { 2. Social co-payments } \\
\text { BGN/ month. } \\
\text { 3. Additional incentives } \\
\text { BGN / month } \\
\text { 4. Temporary hired / } \\
\text { number of months per year } \\
\text { 5. Basic salary and } \\
\text { benefits of temporary } \\
\text { workers in the BGN / } \\
\text { month } \\
\text { 6. Social co-payments of } \\
\text { temporary BGN/month } \\
\text { 7. Additional incentives of } \\
\text { temporary BGN/ month }\end{array}$ \\
\hline
\end{tabular}

To achieve greater depth of research, the business organizations are also considered by type according to their legal and organizational structure. These include the Sole-Owner Limited Liability Companies /Ltd./, which are 35\% of the total surveyed, the Limited Liability Companies /LLC/, whose share is $42 \%$, and Joint Stock Companies /JSC/, with a share of $23 \%$.

In order to construct the model of the main factors influencing the effective management of the subordinate staff, the tools of Path-factor analysis are applied. This method combines the possibilities of correlation, regression and structural analysis, making it one of the most appropriate methods for studying the relationships, as the Path-analysis considers not only the direct but also the indirect links between the employees' management factors and the economic results of the business organizations. In this way, those factors which have the strongest impact are assessed, and those with the weakest influence are eliminated.

The survey covers the period between 2017 and 2019. Data and information are collected through direct contacts, completion of specially developed for the purpose of the analysis reports, tables, company documentation and more. The statistical package SPSS 13.0 and Microsoft Office (Word, Excel and Power Point) are used for data processing and analysis. 


\section{Results and discussion}

A study of the influence of the factors for the subordinate staff management on the economic results in the Bulgarian quarrying organizations.

Influence of the factors "Number, structure and professional experience of the subordinate staff"

The analysis of the factors "Number, structure and professional experience" covers the relationship between those relating to the number of permanent and temporary employees, age and gender structure, as well as the length of service of the subordinate staff, and the economic condition of the surveyed companies (Table 2).

Table 2. Influence of the factors "Number, structure and professional experience of the subordinate staff".

\begin{tabular}{|l|c|c|c|c|}
\hline $\begin{array}{r}\text { Correlation } \\
\text { coefficient }\end{array}$ & Total & Ltd. & LLC & JSC \\
Factors & & & & \\
\hline 1. Number of all employed in the organization & 0.869 & 0.833 & 0.924 & 0.667 \\
\hline a/ Permanent subordinate staff; & 0.811 & 0.697 & 0.861 & 0.684 \\
\hline b/ Temporary staff. & -0.056 & -0.138 & 0.018 & -0.183 \\
\hline 2. Age groups & 0.628 & 0.618 & 0.551 & 0.636 \\
\hline a/ From 15 to 35 & 0.816 & 0.417 & 0.844 & 0.729 \\
\hline b/ From 36 to 55 & 0.447 & 0.495 & 0.189 & 0.339 \\
\hline c/ Over 56 & 0.521 & 0.477 & 0.633 & 0.637 \\
\hline 3. Gender & 0.479 & 0.586 & 0.398 & 0.423 \\
\hline a/ Men & 0.449 & 0.524 & 0.396 & 0.379 \\
\hline b/ Women & 0.583 & 0.423 & 0.754 & 0.643 \\
\hline 4. Work experience & 0.336 & 0.294 & 0.258 & 0.398 \\
\hline a/ To 15 yrs. & 100 & 37 & 27 & 36 \\
\hline b/ From 16 to 35
\end{tabular}

In terms of age structure, particularly important for achieving positive economic results are the workers between 36 and 55 years of age. Their interaction with the generated profit is proved statistically with a high correlation coefficient $/ \mathrm{R}=0.816$ at $\alpha=0.01 /$. The employees from this age group have a strong influence in the capital companies, too, respectively in LLC with $\mathrm{R}=0.844$ at $\alpha=0.01$ and in JSC with $\mathrm{R}=0.729$ at $\alpha=0.01$. In the age group below 35 there is also a statistically proven interdependence with the realization of good production and economic performance. The influence of this age group is especially remarkable in Ltd. $/ \mathrm{R}=0.618$ at $\alpha=0.05 /$. The weakest contribution to the achievement of positive economic performance is reported in the age group 56-over. This indicates that the subordinate workers below 55 are carriers of the main charge for the development of the economic organizations from the mining industry in Bulgaria.

The analysis of the gender structure of the subordinate staff shows relatively similar levels of correlation coefficients for men $/ \mathrm{R}=0.521 /$ and for women $/ \mathrm{R}=0.479 /$. With regard to the types of business organizations according to their legal and economic statute, women with $\mathrm{R}=0.586$ at $\alpha=0.05$ are more significant for achieving positive economic results in the Ltd. In the other two groups, the leading role of men is statistically proven. This leads to the conclusion that the selection of the subordinate staff in terms of gender structure should be subject to the requirements of the specific activity and tasks performed.

The length of service is a factor which takes into account the degree of experience gained by the subordinate employees. The study reveals a strong correlation between the realized profit and the workers with work experience between 16 and 35 years $/ R=0.583$ at $\alpha=0.05 /$. 
With Ltd., employees with up to 15 years of service are of particular value for the ultimate positive results, while with LLC and JSC, the strongest influence is reported at subordinate staff with 16 to 35 years of experience $/ R=0.583$ at $\alpha=0.05 /$. In the case of Ltd., the workers with up to 15 years of professional experience are of special importance for the final positive results, while in the case of LLC and JSC, the highest influence is evidenced among the subordinate staff with 16 to 35 years of service. We could conclude that the implementation of innovative ideas, as well as the quality use of new techniques and technologies, are not a priority for those with the longest work experience. In this respect, better performance of the assigned production tasks and superior final economic results are achieved by subordinates with not too long production experience.

Influence of the factors "Educational and professional qualification profile of the subordinate staff"

The practical application of "good" production practices, the implementation of European standards, as well as the handling of modern techniques and technologies are possible only with well-selected subordinate staff, possessing the necessary level of education, qualifications and professional experience. Therefore, it is of highest importance to study the educational and vocational qualification profile of the subordinate workers and its impact on the production and economic performance of the mining organizations in Bulgaria.

From the data recorded, the "Education" factor shows a very strong proportional interdependence between the subordinate staff with secondary special education and the realization of profit in the surveyed businesses. This factor shows a very high correlation coefficient of 0.823 at $\alpha=0.01$. /Table 3./ Its significance is evident in all types of business organizations, as the strongest influence is in LLC with $\mathrm{R}=0.876$ at $\alpha=0.01$. The results for Ltd. with $\mathrm{R}=0.659$ at $\alpha=0.05$ and JSC with $\mathrm{R}=0.804$ at $\alpha=0.01$ are similar.

Another important factor for achieving positive economic outcome in the surveyed organizations is the subordinate staff with higher education $/ \mathrm{R}=0.664$ at $\alpha=0.01 /$. In this respect, its strong influence is statistically proved in LLC - R $=0.636$ at $\alpha=0.01$, as well as in JSC - R $=0.659$ at $\alpha=0.01$. The other studied levels of education have a weaker impact on the positive economic performance, and for employees with primary education there is even a negative correlation. Workers with elementary and primary education in LLC and JSC also render such a negative impact on profit. The presented data indicate that the high level of education of the subordinate staff is a prerequisite for achieving better economic results. A well-trained worker with specialized knowledge will more easily perceive and apply innovations, which will lead to faster and better performance of his/ her production tasks. For the subordinate personnel, the research also covered the impact of the acquired professional experience on achieving positive economic results. The data show a strong, statistically proven correlation between the realized profit and the subordinate staff with experience in the specialty below 15 years $/ \mathrm{R}=0.501$ at $\alpha=0.05 /$, as well as those with professional experience from 16 to 35 years $/ \mathrm{R}=0.588$ at $\alpha=0.01 /$. Similar results are reported for all three types of business organizations according to their legal and organizational status. This indicates that the quality of the practical implementation of the tasks set and the achievement of good production and economic results is not always directly linked to the length of the acquired professional experience.

Influence of factors "Efficiency of use of the subordinate staff".

The study of the factors demonstrating the efficiency of the use of the subordinate staff covers the achieved results in labor productivity. We analyzed the level of output /BGN, per one worker and per one man-day in BGN/, as well as the productivity of the subordinate staff in their interaction with the economic results of the holdings in the Bulgarian extractive industry.

The analysis hereby performed reveals a statistically proven strong relationship between the factors in this group and the generated profit for the period in focus. In their majority, the 
results obtained show a significant positive correlation between the efficiency of the use of subordinate staff and the economic performance of the businesses. Concerning the types of business organizations according to their legal and organizational status, there is a strong impact of the factors " Produced output/ BGN " and " Produced output per person-day of the subordinate staff/ BGN". The data from the survey prove that the labor efficiency of the subordinate personnel plays a key role in achieving elevated production and economic results in the mining organizations in Bulgaria.

The adequate level of remuneration and additional labor stimuli are key factors for retaining qualified professionals and developing economically viable businesses. This necessitates the research on the impact of the basic salary, social benefits and supplemental incentives on the obtained positive economic results for the period (Table 3).

Table 3. Influence of the factors "Educational and professional qualification profile of the

\begin{tabular}{|l|c|c|c|c|}
\hline \multicolumn{1}{|c|}{$\begin{array}{c}\text { Correlation } \\
\text { coefficient }\end{array}$} & Total & Ltd. & LLC & JSC \\
\hline $\begin{array}{l}\text { Factors } \\
\text { 1. Basic salary and social security of }\end{array}$ & 0.628 & 0.511 & 0.669 & 0.584 \\
\hline 2. Social co-payments BGN/ month. & -0.051 & 0.229 & -0.117 & -0.083 \\
\hline 3. Additional incentives BGN / month & 0.423 & 0.368 & 0.443 & 0.497 \\
\hline $\begin{array}{l}\text { 4. Temporary hired / number of months per } \\
\text { year }\end{array}$ & -0.117 & 0.139 & -0.066 & -0.124 \\
\hline $\begin{array}{l}\text { 5. Basic salary and benefits of temporary } \\
\text { workers in the BGN / month }\end{array}$ & 0.236 & 0.217 & 0.254 & 0.111 \\
\hline $\begin{array}{l}\text { 6. Social co-payments of temporary } \\
\text { BGN/month }\end{array}$ & -0.034 & -0.023 & -0.128 & 0.006 \\
\hline $\begin{array}{l}\text { 7. Additional incentives of temporary BGN/ } \\
\text { month }\end{array}$ & 0.116 & 0.182 & 0.213 & 0.239 \\
\hline Organizations Studied. \% & 100 & 37 & 27 & 36 \\
\hline
\end{tabular}

The survey of the subordinate staff covers their remuneration and labor incentives,

From the presented record it is clear that a proven correlation dependence is observed in the basic payment of permanent employees with $\mathrm{R}=0.631$ at $\alpha=0.05$, as well as in their additional stimuli with $\mathrm{R}=0.439$ at $\alpha=0.05$. The strong influence of the basic payment is accounted for by all three types of business entities according to their legal and organizational structure. The effect of supplemental stimulation is statistically demonstrated at LLC with $\mathrm{R}$ $=0.498$ at $\alpha=0.05$ and at JSC with $\mathrm{R}=0.536$ at $\alpha=0.05$. In the Ltd. holdings there are moderate levels of significance of the factors Supplementary stimulation and Social benefits. With LLC and JSC, social benefits result in a negative impact on the final economic performance. From the presented record it can be concluded that the adequate payment, as well as the additional incentives for the permanently hired subordinate staff, are a crucial condition for achieving high production and economic results.

The survey on the temporary laborers does not establish a statistically proven relationship between the factors in this group and the profit generated during the period in focus. We detect low levels of interaction with the basic wage and additional incentives. Both, the number of months of hiring annually, as well as the social benefits reflect negatively on the final economic performance. These data show that the temporary hiring of subordinate staff is not an acceptable alternative for improving the economic condition of the companies in the mining industry. The search for opportunities to reduce or completely eliminate temporary employment will largely stimulate the achievement of higher production results.

The presented analysis shows the interrelation and influence of the factors of the subordinate staff management on the economic condition of the quarrying companies in 
Bulgaria. Based on this thesis, we can propose a combination of factors which have the greatest influence on the economic performance.

Modeling of the factors for the subordinate staff management which directly or indirectly influence the high economic results of the Bulgarian quarrying industry.

In order to study the strength of the impact of both direct and indirect links of the subordinate staff management factors on the economic condition of the companies in the extractive industry, we applied the method of Path-analysis. This method evaluates only those factors which result in the strongest impact on the economic performance, while the weak ones are eliminated. The results obtained from the Path analysis performed on the subordinate staff are shown in Table 4.

Table 4. Direct and indirect effect of the subordinate staff management factors

\begin{tabular}{|l|c|c|}
\hline \multicolumn{1}{|c|}{ Path-coefficient } & Direct impact & Indirect impact \\
\hline Factors & 1,006 & $-0,137$ \\
\hline 1. Number of employees in the organization & 0,577 & 0,234 \\
\hline 2. Permanent subordinate staff & 0,746 & $-0,118$ \\
\hline 3. Subordinate staff aged 15 to 35 & 0,477 & 0,339 \\
\hline 4. Subordinate staff aged 36 to 55 & 0,577 & $-0,076$ \\
\hline 5. Work experience on the specialty to 15 yrs. & 0,377 & 0,211 \\
\hline 6. Work experience on the specialty from 16 to 35 yrs. & 0,559 & 0,264 \\
\hline 7. Vocational secondary education & $-0,104$ & 0,768 \\
\hline 8. Higher education & 0,302 & 0,381 \\
\hline 9. Produced output/ BGN & $-0,116$ & 0,584 \\
\hline 10. Produced output per one person-day/ BGN & 0,573 & 0,111 \\
\hline $\begin{array}{l}\text { 11. Produced output per person-day of the subordinate staff/ } \\
\text { BGN }\end{array}$ & 0,434 & 0,194 \\
\hline $\begin{array}{l}\text { 12. Basic salary and social security of employees in the BGN / } \\
\text { Month }\end{array}$ & 0,651 & $-0,228$ \\
\hline 13. Additional incentives BGN / month & $-0,347$ & 0,463 \\
\hline 14. Additional incentives of temporary BGN/ month & & \\
\hline
\end{tabular}

The records in the table indicate that the number of permanently employed subordinate staff, aged between 36 and 55, with vocational experience below 35 years and secondary special education are the factors which have the strongest impact on achieving high economic results in the economic organizations from the mining sector. They reveal a positive direct and indirect effect. This group also includes the factors related to the total production and the production for one man-day of the subordinate employees, as well as their basic salary. Its direct and indirect positive interaction with the profit is largely related to the strong motivating effect of the adequate remuneration for the hard work.

The direct positive influence of the factors, related to the total number of employees in the businesses, the subordinate staff aged 15 to 35 with experience in the specialty below 15 years, as well as the additional stimulation of the permanently employed subordinates, is, however, somehow decreased from their indirect but negative effect.

The third group, including the factors with direct negative and indirect positive effect, covers the production for one man-day of the subordinate staff/ BGN, as well as the supplementary stimulation of the temporarily hired workers. A negative direct effect is also observed with regard to the subordinate staff with higher education. Although the direct impact of these factors on the final economic performance is negative, the indirect positive impact is stronger, leading to the ultimate positive effect.

A model of the major factors which have a direct and indirect impact on the economic condition of the organizations from the mining industry in Bulgaria is presented in Fig.1. 


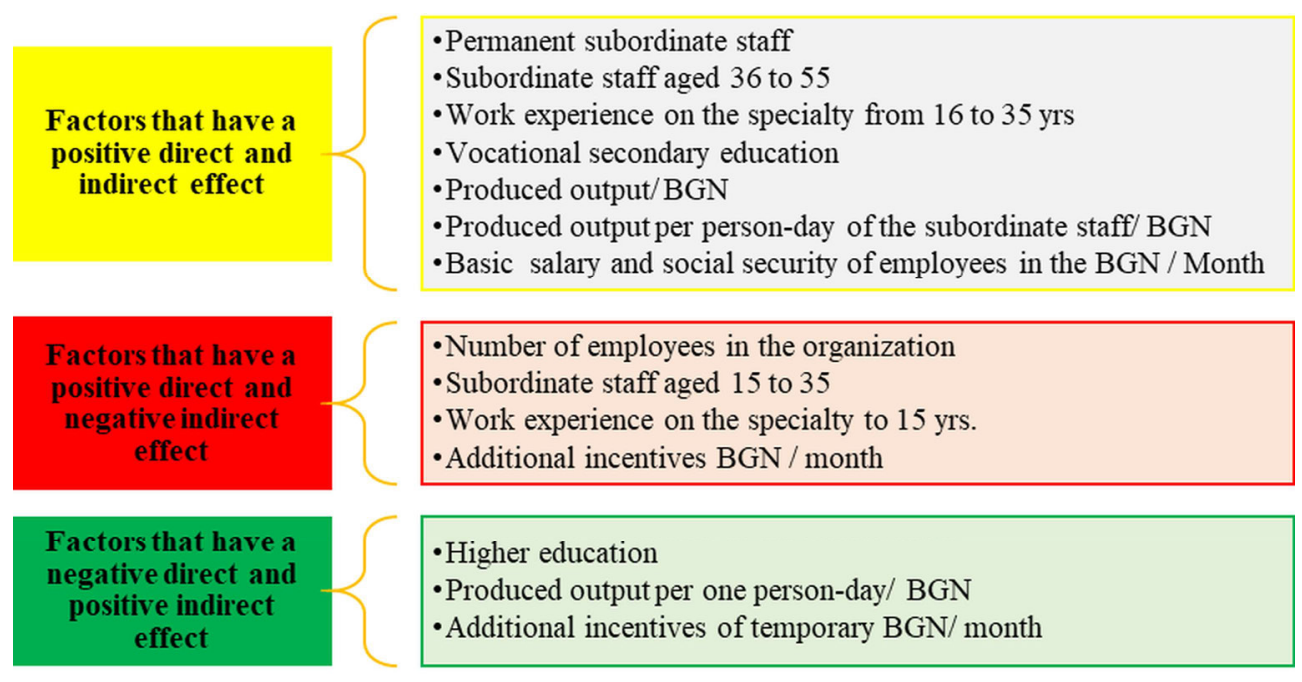

Fig. 1. Model of the factors for the subordinate staff management which directly or indirectly influence the high economic results of the Bulgarian quarrying industry.

The modeling of the factors for the subordinate staff management as well as their action and interaction for achieving high economic results in the quarrying sector in Bulgaria is of paramount importance for the establishment of a system for selection, training and professional development. The implementation of such a system is an important prerequisite for increasing the efficiency of the management, leading to the achievement of sustainability and development of the companies in Bulgaria.

\section{Conclusion}

In modern conditions, when knowledge, skills and competencies have become the driving force in the development of the businesses, the role of properly selected subordinate personnel is growing. Not only formal education, but also its quality and consistency with the current and future needs of the economy are of primary value. The current study and the analysis of the factors of subordinate personnel management in the holdings of the Bulgarian extractive industry lead us to the following conclusions.

Of particular importance for the positive economic outcome is the optimal number of subordinate employees, which is why it is important to periodically review the balance between necessary and available labor.

The successful realization of the planned activities, which lead to the achievement of higher production and economic results, is mainly due to the permanently hired subordinate staff. The transition from temporary to permanent forms of employment will lead to improvement of the microclimate in the business organizations, to increase of motivation of the employees for qualitative and exact execution of the management decisions and achievement of better economic results.

The actual implementation of "good" production practices, of the European standards, as well as the application of modern techniques and technologies are possible only with wellselected subordinate employees, possessing the necessary level of education, qualifications and professional experience. A high level of education for the subordinates is a prerequisite for achieving high economic results. The well-trained and competent worker will easily perceive and apply innovations, which, in turn, leads to faster execution and better quality of the production tasks. 
The adequate levels of remuneration and additional work incentives are key factors in retaining skilled professionals and developing economically viable business organizations. This factor is especially significant during an economic crisis, when the material stimulus outweighs and overrides the rest of the motivating incentives.

\section{References}

1. A. Zahariev, M. Zveryakov, S. Prodanov, G. Zaharieva, P. Angelov, S. Zarkova, M. Petrova, Entrepreneurship and Sustainability Issues, 7:3, 2382-2393 (2020)

2. R. Pukala, M. Petrova, E3S Web Conf., 105, 04034 (2019)

3. N. Kurmanov, M. Petrova, S. Suleimenova, E3S Web Conf., 105, 04045 (2019)

4. I. Kolechkina, I. Verchagina, E. Eltsova, M. Petrova, E3S Web Conf., 134, 02004 (2019)

5. A. Zagorodnya, N. Dichek, N. Chobitko, M. Voznyk, L. Honchar, M. Petrova, International Journal of Higher Education, 9:3, 139-144 (2020)

6. K. Mussapirov, J. Djalkibaev, G. Kurenkeyeva, A. Kadirbergenova, M. Petrova, L. Zhakypbek, Entrepreneurship and Sustainability Issues, 7:2, 1480-1495 (2019)

7. V. Koval, G. Duginets, O. Plekhanova, A. Antonov, M. Petrova, Entrepreneurship and Sustainability, 6:4, 1922-1937 (2019)

8. O. Baklanova, M. Petrova, V. Koval, Economic Studies, 29:1, 68-91 (2020) 